\title{
Assessment of Nutritional Status AmongPrimary School Pupils in Rural and Urban Areas of Anambra State
}

\author{
Nwabueze Achunam Simeon ${ }^{1}$, Ilika Amobi Linus ${ }^{1}$, Azuike Emmanuel Chukwunonye ${ }^{1, ~ *, ~}$ \\ Nwabueze Nneka Chidimma ${ }^{1}$, Obi Kamtoochukwu Mmaduneme ${ }^{1}$, Onebunne Michael Emeka ${ }^{1}$, \\ Enwonwu Kenechukwu Grace ${ }^{1}$, Aniagboso Clifford Chidiebere ${ }^{1}$, Ezenyeaku ChijiokeAmara ${ }^{1}$, \\ Ajator Chioma Chetachukwu', Azuike Ebele Dabeluchukwu
}

\author{
${ }^{1}$ Department of Community Medicine, Nnamdi Azikiwe University Teaching Hospital, Nnewi, Nigeria \\ ${ }^{2}$ Department of Nursing Science, College of Health Sciences, Nnamdi Azikiwe University, Awka, Nigeria
}

Email address:

emmanazuike@yahoo.com (Azuike E. C.)

\section{To cite this article:}

Nwabueze Achunam Simeon, Ilika Amobi Linus, Azuike Emmanuel Chukwunonye, Nwabueze Nneka Chidimma, Obi Kamtoochukwu Mmaduneme, Onebunne Michael Emeka, Enwonwu Kenechukwu Grace, Aniagboso Clifford Chidiebere, Ezenyeaku Chijioke Amara, Ajator Chioma Chetachukwu, Azuike Ebele Dabeluchukwu. Assessment of Nutritional Status Among Primary School Pupils in Rural and Urban Areas of Anambra State. European Journal of Preventive Medicine. Vol. 3, No. 2, 2015, pp. 34-38. doi: 10.11648/j.ejpm.20150302.14

\begin{abstract}
Background: Malnutrition is a common problem in Sub-Saharan Nigeria. The untoward effects of malnutrition on children cannot be overemphasized. There is need for studies to understand the dynamics of malnutrition in order to intervene appropriately. Nutritional assessment in the community is essential for accurate planning and implementation of intervention programmes to reduce mortality and morbidity associated with malnutrition. Objectives: This study was carried out to assess the nutritional status of primary school pupils in urban and rural areas of Anambra state, compare them and find out the factors that affect their nutritional status. Methodology: A cross sectional comparative study of 365 children selected by stratified random sampling method from primary schools in both urban and rural areas of Anambra state was carried out. Their nutritional status was determined using anthropometric measures. The socioeconomic and socio demographic variables of interest were analyzed to determine their association with malnutrition in the children. Results: Three hundred and sixty five pupils participated in the study. Among the pupils 181 were in the rural area while 184 were in the urban area. The overall prevalence of underweight, stunting and overweight were $10.7 \%, 1.9 \%$ and $4.1 \%$ respectively. Prevalence of underweight was higher in the rural area (18.8\%) than in the urban area $(2.7 \%)$ and the difference was statistically significant. The prevalence of stunting was higher in the rural area $(3.3 \%)$ than in the urban area $(0.5 \%)$ and the difference was statistically significant. Underweight was more among the pupils whose parents had low educational level than among those whose parents had higher educational level, and the difference was statistically significant. Conclusion: Malnutrition is higher in the rural areas than the urban areas in Anambra state. Low level of education of parents predisposes children to malnutrition.
\end{abstract}

Keywords: Nutritional Status, Primary School Pupils, Urban and Rural

\section{Introduction}

School age is a dynamic period of physical growth and mental development of a child. The World Health Organization(WHO) states that nutritional deficiencies and poor health in primary school age children are among the causes of low school enrolment, high school absenteeism, early dropout from school and poor classroom performance. ${ }^{(1)}$ Nutritional assessment in the community is essential for accurate planning and implementation of intervention programmes to reduce mortality and morbidity associated with malnutrition. ${ }^{(2)}$ In India,National family health survey data shows that $53 \%$ of children in rural areas are underweight and this varies across states. ${ }^{(3)}$ This is not different from the unsatisfactory health and nutritional status of the children in Nigeria currently,as in the work carried out in Ile Ife Central LGA in which $70.5 \%$ of children in rural areas were underweight as compared to their urban counterpart which were $2.2 \%$. $^{(4)}$

Nutritional status is the current body status of a person or a population group, related to their state of nourishment (the consumption and utilization of nutrients). This is determined 
by a complex interaction between internal/constitutional factors and external/environmental factors. Some of these internal factors include age, sex, nutrition, behaviour, physical activity and diseases while the external factors include food safety, cultural, social and economic circumstances. There is increased risk of malnutrition than over-nutrition in children from poor socioeconomic families where the nutrition intake is reduced. ${ }^{(2)}$ Some disease conditions can also cause reduced absorption of nutrients in the body leading to malnutrition. ${ }^{(5)}$ Some methods of assessment of nutritional status include anthropometric measurement,biochemical or laboratory tests, dietary assessment and clinical assessment. Body mass index is a global measure of nutritional status. It illustrates the differences between the sensitivity and specificity of the technique. It provides more accurate results than other methods. ${ }^{(5)}$ There is need to assess the nutritional status of children in rural and urban. This is becausenutritional status is an important indicator in the progression of child's development and growth.Though works has been done on nutritional status of children in Anambra state, they were on secondary school children. The aim of this study was to assess the nutritional status of primary school children in urban and rural communities of Anambra state.

\section{Methodology}

It was conducted in Anambra State. Anambra state is in the south-eastern part of Nigeria. It is the $8^{\text {th }}$ most populated in Nigeria and $2^{\text {nd }}$ most densely populated after Lagos. It has 21 Local Government Areas ( 7 urban areas and 14 rural). The urban LGAs include: Nnewi-North, Awka-South, OnitshaNorth, Ihiala, Idemili-North, Aguata, Orumba-South. The rural LGAs include: Awka-North, Anambra-East, AnambraWest, Anaocha, Ayamelum, Dunukofia, Ekwusigo, IdemiliSouth, Njikoka, Nnewi-South, Ogbaru, Onitsha-South and Orumba-North.

This wasa cross-sectional comparative study.The study population comprised of all primary school pupils in urban and rural areas of Anambra State.

The sample size was calculated using the formula for calculation of sample size in a comparative study ${ }^{(6)}$ :

$$
n=\frac{2 z^{2} p q}{d^{2}}
$$

$\mathrm{n}=$ The desired sample size

$\mathrm{z}=$ The standard normal deviate at $95 \%$ confidence interval $=1.96$.

$\mathrm{P}=$ The proportion in the target population estimated to have a particular characteristic. Prevalence of malnutrition in a study in Sagamu $=39.4 \%$. ${ }^{(7)}$ Therefore $\mathrm{P}=0.39$

$\mathrm{q}=1.0-\mathrm{P}=0.61$.

$\mathrm{d}=$ Degree of accuracy desired, set at 0.10 for comparative study.

$$
n=\frac{2(1.96)^{2} \times 0.39 \times 0.61}{0.10^{2}}=182.78=183 \text { pupils. }
$$

$\mathrm{n}=181$ in rural area

$\mathrm{n}=184$ in urban area

There are six levels in a primary school so to get the number per class, 181pupils in rural areawere divided by 12 making it 16 pupilsper level and 184 pupils in urban areas were also divided by 12 making it 16 pupils per level..

Multistage Sampling technique was used. Stage 1: The schools were stratified into rural and urban. Stage 2: Simple Random Sampling was used to select one rural and one urban area. Stage 3: Stratified sampling was used: the primary schools were divided into public and private schools. Stage 4: Simple Random Sampling was used to selectone public and one private school per Local Government Area. Stage 5: Sixteen participants were taken per class. Data was collected using a semi-structured questionnaire.

Data collected was analysed using Statistical Package for Social Sciences (SPSS) version 20.

The results were presented using tables and charts. Chi square was used for to test for associations. P value of $<0.05$ was considered significant.Permission for this study was obtained from Nnamdi Azikiwe University Teaching Hospital Ethical Committee. Written informed consent was obtained from the parents of the pupils and assent was obtained from the pupils.

\section{Results}

\begin{tabular}{|c|c|c|}
\hline Variables & Frequency & Percentage \\
\hline \multicolumn{3}{|l|}{ Age(yrs) } \\
\hline$<5$ & 6 & $1.6 \%$ \\
\hline $6-10$ & 250 & $68.5 \%$ \\
\hline $11-14$ & 107 & $29.3 \%$ \\
\hline$\geq 15$ & 2 & $0.5 \%$ \\
\hline \multicolumn{3}{|l|}{ Sex } \\
\hline Male & 184 & $50.4 \%$ \\
\hline Female & 181 & $49.6 \%$ \\
\hline \multicolumn{3}{|l|}{ Present class in school } \\
\hline Primary 1 & 56 & $15.3 \%$ \\
\hline Primary 2 & 61 & $16.71 \%$ \\
\hline Primary 3 & 63 & $17.3 \%$ \\
\hline Primary4 & 70 & $19.2 \%$ \\
\hline Primary 5 & 54 & $14.8 \%$ \\
\hline Primary 6 & 61 & $16.7 \%$ \\
\hline \multicolumn{3}{|l|}{ School } \\
\hline Private & 181 & 50.4 \\
\hline Public & 184 & 50.4 \\
\hline \multicolumn{3}{|l|}{ Residents } \\
\hline Urban & 184 & $50.4 \%$ \\
\hline Rural & 181 & $49.6 \%$ \\
\hline \multicolumn{3}{|c|}{ Mothers highest level of education } \\
\hline None & 16 & $4.4 \%$ \\
\hline Primary & 15.5 & $42.5 \%$ \\
\hline Secondary & 138 & $37.8 \%$ \\
\hline Tertiary & 55 & $15.1 \%$ \\
\hline Deceased & 1 & $0.3 \%$ \\
\hline \multicolumn{3}{|l|}{ Mother's occupation } \\
\hline Civil servant & 60 & $16.4 \%$ \\
\hline Trader/business woman & 218 & $59.7 \%$ \\
\hline Self employed professional & 11 & $3.0 \%$ \\
\hline Clergy & 1 & $0.3 \%$ \\
\hline House wife & 15 & $4.1 \%$ \\
\hline
\end{tabular}

Table 1. Socio-demographic status of the pupils. 


\begin{tabular}{lll}
\hline Variables & Frequency & Percentage \\
\hline Others & 52 & $14.2 \%$ \\
Artisan & 6 & $1.6 \%$ \\
Deceased & 1 & $0.3 \%$ \\
Unemployed & 1 & $0.3 \%$ \\
Father's highest level of education & & \\
None & 16 & $4.4 \%$ \\
Primary & 152 & $41.6 \%$ \\
Secondary & 148 & $40.5 \%$ \\
Tertiary & 42 & $11.5 \%$ \\
Deceased & 7 & $1.9 \%$ \\
Father's occupation & & \\
Unemployed & 1 & $0.3 \%$ \\
Civil servant & 35 & $9.6 \%$ \\
Trader/business man & 142 & $38.9 \%$ \\
Self employed professional & 16 & $4.4 \%$ \\
Clergy & 9 & $2.5 \%$ \\
Others & 95 & $26.0 \%$ \\
Deceased & 9 & $2.5 \%$ \\
\hline
\end{tabular}

Table 1 shows the socio-demographic characteristics of the pupils. There were a total number of 365 pupils and their ages ranged between $4-15 y$ rs. $65.5 \%$ were aged between $6-10$ years, $29.3 \%$ were aged $11-14$ years, $1.6 \%$ were aged $<5$ years and $0.5 \%$ were $\geq 15$ years. The mean age was $9.3 \pm 2.2$ years (mean \pm SD)

Out of 365 pupils, $50.4 \%$ were males and $49.6 \%$ were females.

Table 2. Nutritional status of the children.

\begin{tabular}{lll}
\hline Variables & Frequency & Percentage \\
\hline Weight for age & & \\
Normal weight & 311 & $85.2 \%$ \\
Underweight & 31 & $10.7 \%$ \\
Overweight & 15 & $4.1 \%$ \\
Height for age & & \\
Normal height & 327 & $89.6 \%$ \\
Stunted & 7 & $1.9 \%$ \\
Above normal & 31 & $8.5 \%$ \\
\hline
\end{tabular}

Table 2 shows the weight for age and height for age of the pupils in the school and their frequencies. Normal weight represents those that fall between $3^{\text {rd }}$ and $97^{\text {th }}$ percentile while underweight are for those that fall in the category of less than $3^{\text {rd }}$ percentile while overweight are those pupils above $97^{\text {th }}$ percentile while stunted represents those below the $3^{\text {rd }}$ percentile and above normal represents those above $97^{\text {th }}$ percentile.

Table 3. Distribution of weight for age of the pupils by place of residence.

\begin{tabular}{lllll}
\hline & Urban & & Rural \\
\hline Variable & Frequency & Percentage & Frequency \\
\hline Weight for age & & & & \\
Normal weight & 167 & $90.8 \%$ & 144 & 34 \\
Underweight & 5 & $2.7 \%$ & 3 & $19.6 \%$ \\
Overweight & 12 & $6.5 \%$ & $18.8 \%$ & $1.7 \%$ \\
Total & 184 & $100 \%$ & $100 \%$ & 180 . \\
\hline
\end{tabular}

Table 3 shows the distribution of weight for age of the pupils. Out of 184 pupils in urban areas, 90.8\%(167) were found to have normal weight, $2.7 \%(5)$ were found to be underweight and $6.5 \%(12)$ were found to be overweight.Out of 181 pupils in rural areas, $79 \%(144)$ were found to have normal weight, $18.8 \%(34)$ were found to be underweight and $1.71 \%(3)$ were found to be overweight.

Table 4. Cross tabulation of weight for age of the pupils by their place of residence.

\begin{tabular}{llllll}
\hline \multicolumn{2}{c}{ Place of residence } & & & \\
\hline Weight for age. & UrbanN=184n=(\%) & RuralN=181 $\mathbf{n}=\mathbf{( \% )}$ & TotalN=365n=(\%) & $\mathbf{X}^{\mathbf{2}}$ & P-value \\
\hline Normal weight & $167(90.8 \%)$ & $144(79.6 \%)$ & $311(85.2 \%)$ & 28.642 & 0.00 \\
Underweight & $5(2.7 \%)$ & $34(18.8 \%)$ & $39(10.7 \%)$ & & \\
Overweight & $12(6.5 \%)$ & $3(1.7)$ & $15(4.1 \%)$ & & \\
\hline
\end{tabular}

Table 4 shows a cross tabulation of the weight for age of statistically significant association between their weight for the pupils by their place of residence. There was a age and their place of residence $\left(\mathrm{X}^{2}=28.642, \mathrm{P}=0.00\right)$.

Table 5. Distribution of height for age of the pupils by their place of residence.

\begin{tabular}{|c|c|c|c|c|c|}
\hline & Urban & & & Rural & \\
\hline Height for age & Frequency & Percentage & Height for age & Frequency & Percentage \\
\hline Normal height & 160 & $87.0 \%$ & Normal height & 167 & $92.3 \%$ \\
\hline Stunted & 1 & $0.5 \%$ & Stunted & 6 & $3.3 \%$ \\
\hline Above normal & 23 & $12.5 \%$ & Above normal & 8 & $4.4 \%$ \\
\hline Total & 184 & $100 \%$ & Total & 181 & $100 \%$ \\
\hline
\end{tabular}

Table 5 shows the distribution of the height for age of the pupils by their place of residence. Out of 184 pupils in urban area, $87.0 \%(160)$ had normal height, $0.5 \%(1)$ were stunted and $12.5 \%(23)$ were too tall for age.Out of 181 pupils in the 
rural areas, 92.3\%(167) had normal height, 3.3\%(6) were stunted and 4.4\%(8) were too small.

Table 6. Cross tabulation of height for age of the pupils by their place of residence.

\begin{tabular}{llllll}
\hline \multirow{2}{*}{ Height for age } & residents & & & \\
\cline { 2 - 6 } & UrbanN=184n=(\%) & RuralN=184n=(\%) & TotalN=36.5n=(\%) & $\mathbf{X}^{\mathbf{2}}$ & P-value \\
\hline Normal height & $160(87.0 \%)$ & $167(92.3 \%)$ & $327(89.6 \%)$ & 10.955 & 0.004 \\
Stunted for age & $1(0.5 \%$ & $6(3.3)$ & $7(1.9)$ & & \\
Above normal & $23(12.5)$ & $8(4.4 \%)$ & $31(8.5 \%)$ & & \\
\hline
\end{tabular}

Table 6 shows cross tabulation of the height for age of the pupils with their place of residence. There was a statistically

significant association between their height for age and their place of residence $\left(X^{2}=10.955, p=0.004\right)$.

Table 7. Cross tabulation of mothers' highest level of education and mothers'occupation by the weight for age.

\begin{tabular}{|c|c|c|c|c|c|c|}
\hline \multirow{3}{*}{ Variable } & \multicolumn{4}{|l|}{ Frequency } & \multirow{3}{*}{$\mathbf{X}^{2}$} & \multirow{3}{*}{ p-value } \\
\hline & \multicolumn{4}{|l|}{ Weight for age } & & \\
\hline & Normal weight & Under weight & Overweight & Total & & \\
\hline Mother's highest level of education & & & & & 38.876 & 0.000 \\
\hline None & 13 & 2 & 1 & 16 & & \\
\hline Primary & 125 & 27 & 3 & 155 & & \\
\hline Secondary & 125 & 10 & 3 & 138 & & \\
\hline Tertiary & 47 & 0 & 8 & 55 & & \\
\hline Dead & 1 & 0 & 0 & 1 & & \\
\hline \multicolumn{7}{|l|}{ Mothers' Occupation } \\
\hline Civil servant & 48 & 4 & 8 & 57 & 43.668 & 0.000 \\
\hline Trader/business woman & 184 & 29 & 5 & 218 & & \\
\hline Self employed professional & 10 & 0 & 1 & 11 & & \\
\hline Clergy & 1 & 0 & 0 & 1 & & \\
\hline Housewife & 12 & 2 & 1 & 15 & & \\
\hline Others & 48 & 4 & 0 & 52 & & \\
\hline Artisan & 6 & 0 & 0 & 6 & & \\
\hline Unemployed & 1 & 0 & 0 & 1 & & \\
\hline Deceased & 1 & 0 & 0 & 1 & & \\
\hline
\end{tabular}

Table 7 shows cross tabulation between the mothers' highest level of education by the pupils' weight for age. There was a statistically significant association between the mothers' educational level and the pupils weight for age $\left(x^{2}=38.876, p=0.00\right)$. Also there was a statistically significant association between the mothers' occupation and the weight for age of the pupils $\left(\mathrm{x}^{2}=43.668, \mathrm{p}=0.00\right)$.

Table 8. Cross tabulation of fathers' highest level of education and fathers'occupation by weight for age of the pupils.

\begin{tabular}{llllll}
\hline \multirow{2}{*}{ Variables } & Frequency & & & & $\mathbf{X}^{2}$ \\
\cline { 2 - 6 } & Weight for age & & & & p-value \\
\hline Father's highest level of education & Normal weight & Underweight & Overweight & Total \\
\hline None & 12 & 2 & 2 & 16 & 28.361 \\
Primary & 123 & 26 & 3 & 152 & 0.000 \\
Secondary & 135 & 8 & 5 & 148 \\
Tertiary & 36 & 1 & 5 & 42 & 7 \\
Deceased & 5 & 2 & 0 & & 24.274 \\
Father's occupation & & & & 35 & \\
Civil servant & 29 & 5 & 1 & 142 & \\
Trader/businessman & 12502 & 10 & 10 & 16 & \\
Self employed & 167 & 0 & 0 & 9 & \\
Clergy & 9 & 0 & 0 & 95 & \\
Others & 77 & 18 & 0 & 58 \\
Artisan & 50 & 4 & 4 & 9 \\
Deceased & 7 & 2 & 0 & \\
\hline
\end{tabular}

Table 8 shows Cross tabulation of fathers' highest level of education by weight for age of the pupils. There was a statistically significant association between their fathers' educational level and their weight for age $\left(x^{2}=28.361, p=\right.$ $0.00)$.Also there was no association between the fathers' occupation and weight for age of the pupils $\left(\mathrm{x}^{2}=24.274, \mathrm{p}=\right.$ 0.146).

\section{Discussion}

In this study $10.7 \%$ of the pupils were underweight. This is less than the national average of $18 \%$ according to the 2013 National Demographic and Health Study (NDHS). ${ }^{8}$ Also a higher prevalence of underweight $(25.4 \%)$ was reported in 
Uyo Nigeria. ${ }^{9}$ Worse still $51.7 \%$ of the school children in Ogun state were underweight. ${ }^{10}$

In this study $1.9 \%$ of the pupils were stunted. This is far less than $17.1 \%$ reported in Uyo, Nigeria ${ }^{9}$ and $48.6 \%$ reported in Ogun state, Nigeria. ${ }^{10}$ These differences may be due to the socioeconomic levels of the parents of the pupils in the different environments.

In this study, the proportion of the pupils that were underweight was higher in the rural $(18.8 \%)$ compared with the urban $(2.7 \%)$ and this was statistically significant. In a study in Ife, Nigeria, the prevalence of underweight among the rural pupils was $70.5 \%$ while the prevalence of underweight among the urban pupils was $52.2 \%$.Interestingly the difference was also statistically significant just like in our study. $^{2}$

In this study the prevalence of stunting among the rural pupils was $3.3 \%$ while the prevalence among the urban pupils was $0.5 \%$ and this difference was statistically significant. Higher rates of stunting $(35.8 \%$ among the rural pupils and $19.8 \%$ among the urban pupils) were reported in Ife and there was also a statistically significant difference. ${ }^{2}$

In this study underweight was more among the pupils whose mothers have less education and mothers' educational level had a statistically significant association with weight for age. A study done in Qatar also reported a higher rate of underweight among the children whose mothers had lower educational level, and the difference was statistically significant. ${ }^{11}$ Also the fathers' level of education had a statistically significant associationwith the weight for age of the pupils and underweight was commoner among the pupils whose fathers have lower educational level. This was similar to the finding of a study in Qatar which reported that underweight was higher among pupils whose fathers had lower educational level and the difference was statistically significant. $^{11}$

In conclusion this study has shown that malnutrition is still a problem in Anambra state both in the rural and the urban areas. However it is more in the rural areas. Also low level of mother's and father's education predisposes to malnutrition.

We therefore recommend that the government should channel the interventions to reduce malnutrition to the rural areas. For example the daily school meal program should be concentrated more in the rural areas. Also health education of parents and caregivers should be channelled to the rural areas.

We also want to caution that this study has the limitation of being conducted among school pupils, making it more difficult to apply the findings to out of school children. It is therefore recommended that further studies in the communities and households should be conducted.

\section{References}

[1] Saluja N, Bhatnagar M, Garg SK, Chopra H, Bajpai SK. Nutritional status of urban primary school children in Meerut. The InternetJournal of Epidemiology, 2009; 8(1).

[2] Aziz MF, Devi MN. Nutritional status and eating practices among children aged 4-6 years old in selected urban and rural kindergarten in Selangor Malaysia. Asian Journal of Clinical Nutrition, 2012; 4(4): 116-131.

[3] Iyer UM,Bhoite RM, Sharmistha R. Nutritional status and determinants of malnutrition of urban and rural adolescent children (12-16) years ofVadodara city India. International Journal of Applied Biology and Pharmaceutical Technology, 2011;2(1).

[4] Oninla SO, Owa JA, Onayade AA, Taiwo O. Comparative study of nutritional status of urban and rural Nigerian school children. Journal of Tropical Paediatrics, 2007; 53(1): 39-43.

[5] Katz SH, Weaver WW. Gale encyclopaedia of food and culture. Scribner: New York. 2014.

[6] Araoye MO. Research methodology with statistic for health and social sciences.Nathadex publisher: Ilorin.2008. P120.

[7] Fetuga MB, Ogunlesi TA, Adekanmbi AF, Alabi AD. Nutritional status of semi urban Nigerian school children using the 2009 WHO references population. West African Journal of Medicine, 2011; 30 (5):

[8] National Population Commission (NPC) (Nigeria) and ICF International: Nigeria Demographic and Health Survey 2013. Abuja, Nigeria and Rockville, Maryland, USA: NPC and ICF International, 2014.

[9] Opara DC, Ikpeme EE, Ekanem US. Prevalence of stunting, underweight and obesity in school aged children in Uyo, Nigeria. Pakistan Journal of Nutrition, 2010; 9(5): 459-466.

[10] Olusoga OJ, Abisola RS, Oluwakemi CS. Evaluation of the nutritional status of primary 1 pupils in Abeokuta South Local Government Area of Ogun state, Nigeria. Research Journal of Medical Sciences, 2008; 2(2): 61-64.

[11] Bener A. Prevalence of obesity, overweight and under weight in Qatari adolescents. Food and Nutrition Bulletin, 2006; 27(1): 39-45. 